University of Massachusetts Amherst

ScholarWorks@UMass Amherst

Chemistry Department Faculty Publication Series

Chemistry

1992

\title{
Supercritical carbon dioxide as a carrier for sample introduction in atomic absorption spectrometry
}

\author{
S. R. Bysouth \\ University of Massachusetts Amherst \\ Julian Tyson \\ University of Massachusetts Amherst
}

Follow this and additional works at: https://scholarworks.umass.edu/chem_faculty_pubs

Part of the Analytical Chemistry Commons

\section{Recommended Citation}

Bysouth, S. R. and Tyson, Julian, "Supercritical carbon dioxide as a carrier for sample introduction in atomic absorption spectrometry" (1992). Analytica Chimica Acta. 1404.

Retrieved from https://scholarworks.umass.edu/chem_faculty_pubs/1404

This Article is brought to you for free and open access by the Chemistry at ScholarWorks@UMass Amherst. It has been accepted for inclusion in Chemistry Department Faculty Publication Series by an authorized administrator of ScholarWorks@UMass Amherst. For more information, please contact scholarworks@library.umass.edu. 


\title{
Supercritical carbon dioxide as a carrier for sample introduction in atomic absorption spectrometry
}

\author{
S.R. Bysouth and J.F. Tyson * \\ Department of Chemistry, University of Massachusetts, Amherst, MA 01003 (USA)
}

(Received 27th September 1991)

\begin{abstract}
The use of a supercritical carbon dioxide carrier to transport organic solutions of metal complexes to a heated restrictor is demonstrated as a means of aerosol or vapour generation for sample introduction in flame atomic absorption spectrometry. Calibrations obtained using conventional pneumatic nebulisation of continuously aspirated solutions or using flow injection into a water carrier are compared with those obtained using the carbon dioxide carrier. Injection of solutions of copper pyrrolidinedithiocarbamate in 4-methyl pentan-2-one into a carbon dioxide carrier at 1000 p.s.i. was shown to be 1.2 times more sensitive than injection of the same solutions into a water carrier with conventional nebulisation. The sensitivity of continuous nebulisation of the solutions, however, was not achieved. Dissolution of solid copper acetyl acetonate in supercritical carbon dioxide is demonstrated and subsequent vaporisation followed by atomisation in a heated quartz furnace is shown to occur.
\end{abstract}

Keywords: Atomic absorption spectrometry; Carbon dioxide; Carriers; Sample introduction; Supercritical carbon dioxide

The aspiration rate for pneumatic nebulisers used for flame atomic absorption spectrometry (FAAS), under typical operating conditions, is usually in the range of 3 to $5 \mathrm{ml} \mathrm{min}^{-1}$. At these flow rates not more than $10 \%$ of the aspirated liquid enters the flame due to the need to remove large droplets which make up a large portion of the aerosol. The nebulisers used for inductively coupled plasma spectrometry are usually even less efficient. Starving the flow into the nebuliser can increase the proportion of solution that is transported, but the increase in efficiency does not lead to greater signals because the decreased analyte delivery rate results in greater dilution by the burner gases. The volume of spray chambers, which allow settling out of the large droplets, is unimportant when continuous aspiration of analyte solutions is being performed, but when discrete volumes of sample are nebulised, as in flow injection (FI) introduction, this volume produces dilution of the analyte droplets with carrier droplets and flame gases by the mixing chamber effect. In order to increase the signals obtained using FI-FAAS it is therefore desirable to increase the efficiency of nebulisation and decrease the dilution by flame gases.

Evaporation of the solvent in the droplets produced by the nebuliser using a heated spray chamber reduces the particle size and therefore the amount of analyte retained in the spray chamber, and has been used for FAAS [1] and with removal of the vaporised solvent for inductively coupled plasma (ICP) atomic emission spectrometry [2] and capacitively coupled microwave plasma spectrometry [3].

Alternative non-pneumatic nebulisers, for example ultrasonic [4] and thermospray [5] devices, show some increase in efficiency. The thermospray was originally designed as an interface between a liquid chromatograph and a mass spec- 
trometer but more recently has been applied to introduction of samples into the ICP [6-13] and deposition of analyte in a graphite furnace during FI electrothermal AAS [14]. These nebulisers have not been used for FAAS which may be due to the greater efficiency of the nebulisers currently used. However, a similar principle has been used to connect a liquid chromatograph to a continuously heated graphite furnace for electrothermal AAS detection [15]. The efficiency of these techniques is increased if volatile solvents are used, however organic solvents may cause problems when an ICP is used and can produce large background signals in FAAS.

If the analyte itself is volatile then it is possible to vaporise all the sample so it can be transported to the atom cell. Volatile metal complexes have been vaporised and atomised after being synthesised both off-line [16-20] and on-line [21]. In the latter case, the associated solvent vapour caused problems due to intense background signals. Such volatile metal compounds have also been studied with respect to their behavior during supercritical fluid (SF) chromatography. The chromatographs were interfaced with an ICP [22-24] or microwave induced plasma [25] via a length of heated quartz capillary, which acted as a restrictor, mounted at the base of the plasma torch. The action of this interface may be considered similar to the thermospray though no liquid droplets are produced due to the low boiling point of carbon dioxide, the usual solvent used. Heating is required, however, to counteract the adiabatic cooling on expansion of the gas, which causes freezing of the gas in the restrictor.

In this paper, results obtained using a heated capillary to interface a flow-injection supercritical $\mathrm{CO}_{2}$ system with a spray chamber for flame atomisation or to a quartz tube for furnace atomisation are presented. The signals obtained when copper-pyrrolidine dithiocarbamate complex dissolved in MIBK is introduced into the system are compared with those obtained using a water carrier and for conventional nebulisation. The dissolution of solid copper(II)-acetyl acetonate by supercritical carbon dioxide and its subsequent atomisation in a quartz tube is also demonstrated.
EXPERIMENTAL

\section{Reagents}

Copper solutions of $0-500 \mathrm{ng} \mathrm{ml}^{-1}$ were made from $1000 \mu \mathrm{g} \mathrm{ml}^{-1}$ stock solution (Fisher, Pittsburg, PA) and were extracted according to the method of Kinrade and Van Loon [26] but ammonium pyrrolidinedithiocarbamate (APDC), (BDH, Poole) was used alone without diethylammonium diethyldithiocarbamate. This produced solutions of the complex in MIBK (Fisher). Copper-acetyl acetonate complex was made by extracting with chloroform (Fisher) the complex formed when 50 $\mathrm{ml}$ of a $1000 \mu \mathrm{g} \mathrm{ml}^{-1}$ aqueous solution of copper as nitrate was shaken with $10 \mathrm{ml}$ of $10 \%$ acetyl acetone (Hacac) (Fisher) in water after addition of solid sodium acetate (BDH). The solvent was evaporated and the precipitated complex was then redissolved in chloroform and filtered to remove any remaining sodium acetate before the chloroform was again evaporated. Chromium acetyl acetonate was made in the same way, except the extraction vessel was allowed to stand for $12 \mathrm{~h}$ before the complex solution was drained.

\section{Apparatus}

Manifolds (see Fig. 1) were constructed from 316 stainless-steel LC tubing of $0.38-\mathrm{mm}$ i.d. A 2- $\mu \mathrm{m}$ LC filter unit (25-0105, SSI, State College, PA) was used to contain solid samples. The liquid carbon dioxide (Bone dry, Union carbide, Danbury, CT) was pumped from a cylinder using a reciprocating LC pump (AA-100-S, Eldex, San Carlos, CA), cooled with ethylene glycol-water mixture that was chilled with dry ice. Restrictors consisted of $100 \mathrm{~mm}$ of $50 \mu \mathrm{m}$ i.d. plain silica GC tubing (SGE, Austin, TX), heated at the end to $260^{\circ} \mathrm{C}$ using a small heating block (Fig. 2) that either replaced the nebuliser of a spectrometer (PE 1100B, Perkin-Elmer, Norwalk, CT) or fitted in the entrance to a heated quartz $\mathrm{T}$-cell which fitted into a cell heater (Perkin-Elmer, Uberlingen) which was mounted in a spectrometer (PE 3100, Perkin-Elmer, Norwalk, CT). For experiments where the solubility of $\mathrm{Cu}(\mathrm{acac})_{2}$ was being investigated, all the manifold components after the pressure transducer (Sensometric Inc., Simi Valley, CA) were within an oven (F11, Perkin- 
a.

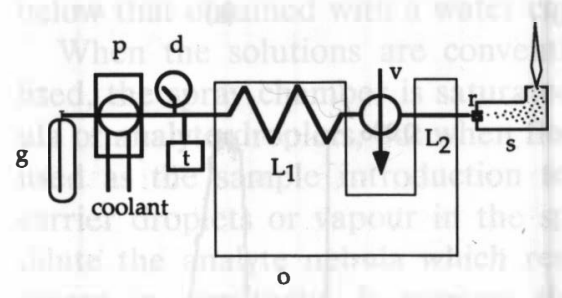

b.

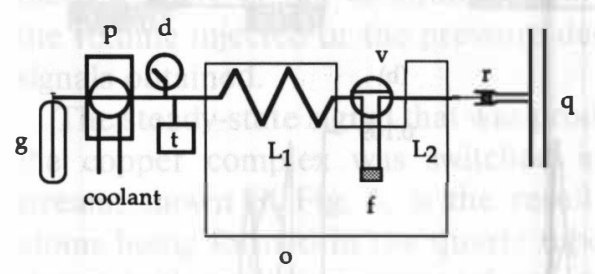

Fig. 1. Manifolds used to (a) investigate the effect of injected volume of complex solution and compare carbon dioxide and water as carriers and (b) study the dissolution of the solid complex and atomisation in a quartz tube. $g$ is the carbon dioxide cylinder, $\mathrm{p}$ the pump, $\mathrm{d}$ a bourdon type pressure gauge, $t$ the pressure transducer, $o$ the oven, $v$ the valve, $r$ the heated restrictor, $f$ the filter unit, $s$ the spray chamber and $q$ the quartz tube. All manifold tubing was $0.38 \mathrm{~mm}$ i.d. stainless steel and length $L_{1}$ was $900 \mathrm{~mm}$ and $L_{2}$ was $320 \mathrm{~mm}$ or 641 $\mathrm{mm}$.

Elmer, Beaconsfield) except approximately 200 $\mathrm{mm}$ of tubing from the oven to the restrictor, and the body of the injection valve (7010, Rheodyne, Cotati, CA). When solutions of complex in MIBK

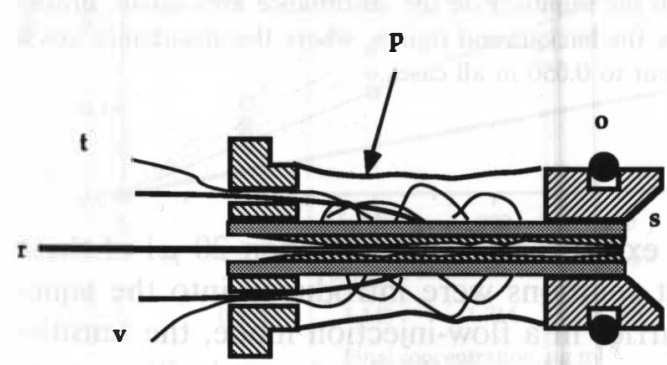

Fig. 2. Restrictor heater. $\mathrm{r}$ is the silica restrictor glued with epoxy based glue into $\mathrm{s}$, a piece of $0.5 \mathrm{~mm}$ i.d. stainless-steel tubing. $v$ is heating wire connected to a variable power source, $t$ are thermocouple wires, $p$ is porcelain cement and $o$ is an 'O'-ring. were introduced, injection loops of 20-101 $\mu$ l were connected to the valve and kept outside the oven.

When the nebuliser was replaced by the restrictor, a $20 \mathrm{~mm}$ length of PTFE tubing, $0.5 \mathrm{~mm}$ i.d., had to be inserted into the air supply of the spray chamber in order that the flame could be lit. This restriction in the air flow mimicked the resistance normally produced by the nebuliser. The flow rates for the air, as given by the spectrometers sensors which rely on this resistance, were therefore invalid and the flame gases were adjusted until a stoichiometric flame was observed. Background correction was used for all the experiments.

\section{Procedures}

Flow injection. Volumes of 20, 40.4, 71 and 101 $\mu l$ of the extracts of $\mathrm{Cu}(\mathrm{PDC})_{2}$ in MIBK were injected into supercritical carbon dioxide via manifold a (Fig. 1) where tube length $L_{2}$ was 641 $\mathrm{mm}$, at pressures of 1000 p.s.i. and 2000 p.s.i., and the resulting peaks were recorded.

Tube $\mathrm{L}_{2}$ was exchanged for a $320-\mathrm{mm}$ length and $20-\mu 1$ volumes of extract were injected into the $\mathrm{CO}_{2}$ carrier stream three times at both 1000 p.s.i. and 2000 p.s.i. The manifold was then disconnected from the restrictor and reconnected to the nebuliser. The $\mathrm{CO}_{2}$ carrier was replaced with water pumped at $4.6 \mathrm{ml} \mathrm{min}^{-1}$ and further $20-\mu \mathrm{l}$ volumes of the extracts were injected. Finally, the extracts were nebulised conventionally.

Solubility of $\mathrm{Cu}(\mathrm{acac})_{2}$ and $\mathrm{Cr}(\mathrm{acac})_{2}$. The restrictor was inserted into the entrance to a quartz $\mathrm{T}$-cell, and a small amount of $\mathrm{Cu}(\mathrm{acac})_{2}$ complex was placed within the filter unit in manifold $b$ (Fig. 1). The cell was then heated to $900^{\circ} \mathrm{C}$ and $\mathrm{CO}_{2}$ was pumped through the system. The valve containing the filter unit was switched into the $\mathrm{CO}_{2}$ stream for a few seconds and the signal recorded. The copper lamp in the spectrometer was then exchanged for a chromium lamp and the monochromator retuned from the $324.8-\mathrm{nm}$ line to the $357.9-\mathrm{nm}$ chromium line before the copper complex was again switched into line. The copper complex was then replaced with $\mathrm{Cr}(\mathrm{acac})_{2}$ which was then switched into line. 
The maximum pressure that could be maintained with the restrictor dimensions used was between 1700 and 2000 p.s.i. Measurements of $\mathrm{CO}_{2}$ flow rate were not performed and use of the pump flow rate calibration is misleading as the $\mathrm{CO}_{2}$ is a compressible fluid.

Representative peaks obtained at different pressures for different volume injections of extracted solutions into $\mathrm{CO}_{2}$ are shown in Fig. 3. At 1000 p.s.i. (the cylinder pressure), increasing the volume injected caused double peaks to form and the signal to decrease. The valleys that occurred when large volumes were injected may have been caused by depression of the signal by the presence of MIBK in the flame which could have altered the flame temperature in a similar manner to that described by Kojima et al. [27] for discrete nebulisation, by movement of the maximum atom population out of the light path or by the behaviour of the restrictor. If the MIBK was preferentially evaporated and the complex was being deposited in the restrictor and then redissolved in the $\mathrm{CO}_{2}$, an increase in the peak that occurs at the end of the slug would be expected as the volume injected was increased. The restrictor heater may not have supplied sufficient heat to evaporate large volumes of solvent and either a jet or aerosol of complex solution may have been formed and lost to the walls of the spray chamber.

Increasing the pressure of $\mathrm{CO}_{2}$ in the system to around 1800 p.s.i. produced an increase in the peak height at the start of the sample slug, even for single peaks. The solubility of MIBK and of the complex in $\mathrm{CO}_{2}$ will increase with increasing pressure which could have increased the dispersion of the sample slug into the $\mathrm{CO}_{2}$ allowing evaporation of the complex at the restrictor. However the overall peak heights decreased compared with those obtained at 1000 p.s.i.

The most sensitive calibration was obtained by conventional nebulisation of the MIBK extracts and is shown in Fig. 4. This calibration is four times more sensitive than conventional nebulisation of aqueous standards of the same concentration as is calculated to be in the extracts assuming (i)

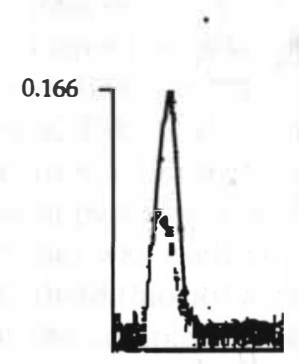

(ii)

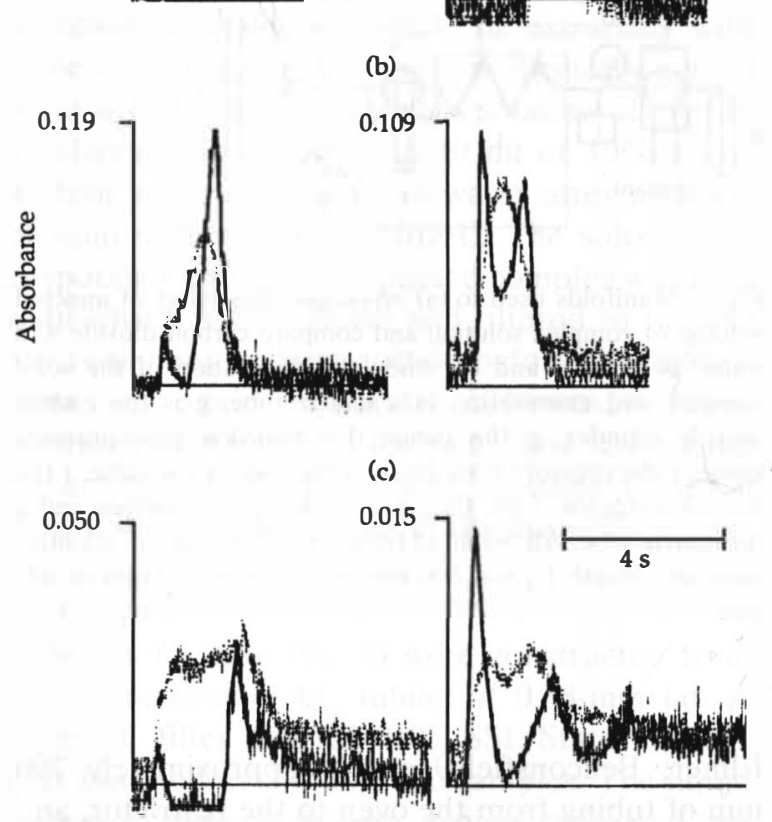

Fig. 3. Typical peaks obtained when different volumes of $\mathrm{Cu}(\mathrm{PDC})_{2}$ dissolved in MIBK are injected into a $\mathrm{CO}_{2}$ carrier at different pressures. (a) $20 \mu \mathrm{l}$; (b) $40.4 \mu \mathrm{l}$; (c) $101 \mu \mathrm{l}$. (i) 1000 p.s.i.; (ii) 1700 p.s.i. Solid lines are traces of absorbance to which the numbers on the absorbance axes relate. Broken lines are the background signals, where the absorbance axis is equivalent to 0.050 in all cases.

$100 \%$ extraction efficiency. When $20 \mu l$ of these extract solutions were introduced into the aqueous carrier in a flow-injection mode, the sensitivity decreased by one third compared with conventional nebulisation. Using a $\mathrm{CO}_{2}$ carrier at 1000 p.s.i. increased the sensitivity but did not restore it back to that obtained by conventional nebulisation of the MIBK solutions. Increasing the pres- 
sure to 1800 p.s.i. decreased the sensitivity to below that obtained with a water carrier.

When the solutions are conventionally nebulised, the spray chamber is saturated with a nebula of analyte droplets, but when flow injection is used as the sample introduction technique, the carrier droplets or vapour in the spray chamber dilute the analyte nebula which results in a decrease in sensitivity. It appears that using the heated restrictor and a $\mathrm{CO}_{2}$ carrier can increase the sensitivity of the calibrations, but increasing the volume injected or the pressure decreases the signals obtained.

The steady-state signal that was produced when the copper complex was switched into a $\mathrm{CO}_{2}$ stream, shown in Fig. 5, is the result of copper atoms being formed in the quartz tube. This was shown both by the presence of an atomic signal with the instrument operated in background correction mode and by checking for absorption of radiation from the chromium lamp, which resulted in no signal. The height of the steady-state signal must depend on a number of factors including the solubility of the complex in the supercritical $\mathrm{CO}_{2}$ will depend on pressure, the flow rate of the $\mathrm{CO}_{2}$ which, for a fixed restrictor orifice size, will also depend on pressure, and the

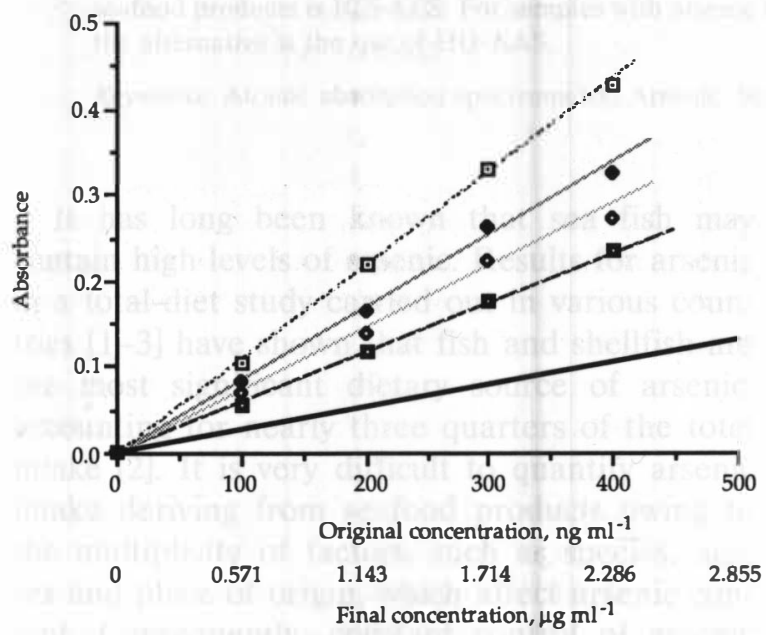

Fig. 4. Calibrations of extracts obtained under the following conditions: ( $\square$ ) conventional nebulisation, $(\diamond)$ carbon dioxide carrier at 1000 p.s.i., ( $\square$ ) carbon dioxide carrier at 2000 p.s.i., $(\diamond)$ water carrier at atmospheric pressure, solid line conventional aqueous nebulisation $\left(0-2.885 \mu \mathrm{g} \mathrm{ml}^{-1}\right)$.

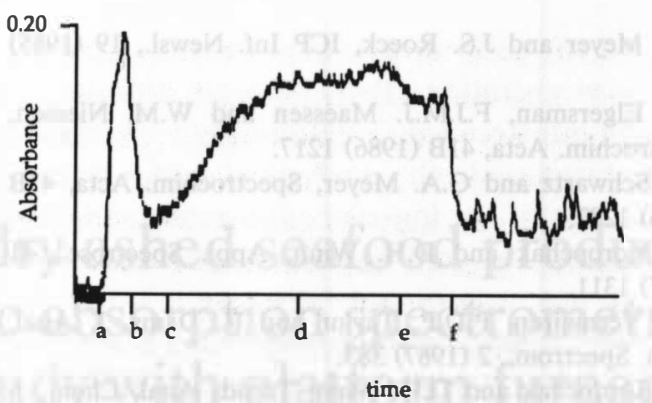

Fig. 5. The signal obtained when the $\mathrm{CO}_{2}$ carrier, flowing into the quartz tube, is passed over solid copper-acac complex. a is the time when the complex is switched into line at 1800 p.s.i. The pressure at b was 1800 p.s.i., c was 1500 p.s.i., d was 1600 p.s.i., e was 1800 p.s.i. The valve was returned at f. Time scale is arbitrary.

atomisation efficiency or atom life time in the quartz tube.

Although the eventual fate of any copper atoms that form must be oxide or other molecular species, the lifetime of the copper atoms formed during breakdown of the complex is sufficient to produce a signal. A small amount of a brown deposit was observed before the entrance to the atomisation area of the T-cell, but no deposit was visible at the ends of the tube. No signal was observed when the same experiment was tried using the chromium complex, but a greater amount of deposit was observed at the T-cell entrance possibly indicating that the cell temperature was high enough to cause decomposition of the complex before reaching the light path. It is likely that any decomposition of the complex would produce oxide species, and that the partial pressure of chromium atoms would not be sufficient to produce a measurable atomic signal.

\section{REFERENCES}

1 A. Gustavsson and O. Nygren, Spectrochim. Acta, 42B (1987) 883.

2 A. Gustavsson, Spectrochim. Acta, 42B (1987) 111.

3 H. Uchida, W. Masamba, T. Uchida, B.W. Smith and J.D. Winefordner, Appl. Spectrosc., 43 (1989) 425.

4 H.C. Hoare, R.A. Mostyn and B.T. Newland, Anal. Chim. Acta, 40 (1968) 181.

5 C.R. Blakeley and M.L. Vestal, Anal. Chem., 55 (1983) 750. 
6 G.A. Meyer and J.S. Roeck, ICP Inf. Newsl., 19 (1985) 955.

7 J.W. Elgersman, F.J.M.J. Maessen and W.M. Niessen, Spectrochim. Acta, 41B (1986) 1217.

8 S.A. Schwartz and G.A. Meyer, Spectrochim. Acta, 41B (1986) 1287.

9 J.A. Koropchak and D.H. Winn, Appl. Spectrosc., 41 (1987) 1311.

10 K.A. Vermeiren, P.D.P. Taylor and R. Dams, J. Anal. Atom. Spectrom., 2 (1987) 383.

11 J.A. Koropchak and D.H. Winn, Trends Anal. Chem., 6 (1987) 171.

12 J.A. Koropchak, H. Aryamanya-Mugisha and D.H. Winn, J. Anal. Atom. Spectrom., 3 (1988) 799.

13 R. Peng, J.J. Tiggelman and M.T.C. Loos-Vollebregt, Spectrochim. Acta, 45B (1990) 189.

14 P.C. Bank, M.T.C. Loos-Vollebregt and L. de Galan, Spectrochim. Acta, 43B (1988) 983.

15 O. Nygren, C.A. Nilsson and W. Frech, Anal. Chem., 60 (1988) 2204.

16 W.R. Wolf, Anal. Chem., 48 (1976) 1717.

17 T. Fujinaga, T. Kuwamoto, K. Isshiki, N. Matsubara and E. Nakayama, Spectrochim. Acta, 38B (1983) 1011.
18 J.R. Castillo, J.M. Mir and C. Bendicho, Fresenius' Z. Anal. Chem., 328 (1987) 56.

19 J.R. Castillo, J.M. Mir and C. Bendicho, J. Anal. Atom. Spectrom., 4 (1989) 105.

20 J.R. Castillo, J. Delfa, J.M. Mir, C. Bendicho, M. de la Guardia, A.R. Mauri, C. Mongay and E. Martinez, J. Anal. Atom. Spectrom., 5 (1990) 325.

21 J.F. Tyson, C.E. Adeeyinwo and S.R. Bysouth, J. Anal. Atom. Spectrom., 4 (1989) 191.

22 J.W. Olesik and S.V. Olesik, Anal. Chem., 59 (1987) 796.

23 C. Fujimoto, H. Yoshida and K. Jinno, J. Chromatogr., 411 (1987) 213.

24 J. Jinno, H. Mae and C. Fujimoto, J. High Resolut. Chromatogr., 13 (1990) 13.

25 C.B. Motley, M. Ashraf-Khorassani and G.D. Long, Appl. Spectrosc., 43 (1989) 737.

26 J.M. Kinrade and J.C. Van Loon, Anal. Chem., 46 (1974) 1894.

27 I. Kojima, N. Nakashima, H. Isoyama, T. Uchida and C. Iida, J. Anal. Atom. Spectrom., 3 (1988) 583. 